\title{
Cost of Living Variation, Nonmetropolitan America, and Implications for the Supplemental Poverty Measure
}

\author{
J. Tom Mueller ${ }^{1}$ D $\cdot$ Matthew M. Brooks ${ }^{2} \cdot$ José D. Pacas $^{3}$ \\ Received: 19 May 2021 / Accepted: 2 February 2022 / Published online: 11 February 2022 \\ (C) The Author(s), under exclusive licence to Springer Nature B.V. 2022
}

\begin{abstract}
Poverty scholarship in the United States is increasingly reliant upon the Supplemental Poverty Measure (SPM) as opposed to the Official Poverty Measure of the United States for research and policy analysis. However, the SPM still faces several critiques from scholars focused on poverty in nonmetropolitan areas. Key among these critiques is the geographic adjustment for cost of living employed in the SPM, which is based solely upon median rental costs and pools together all nonmetropolitan counties within each state. Here, we evaluate the current geographic adjustment of the SPM using both microdata and aggregate data from the American Community Survey for 2014-2018. By comparing housing costs, tenure, and commuting, we determine that median rent is likely an appropriate basis for geographic adjustment. However, by demonstrating the wide variability between median rents of nonmetropolitan counties within the same state, we show that the current operationalization of this geographic adjustment could be improved through the use of more-specific categories such as metropolitan adjacency or Rural Urban Continuum Codes.
\end{abstract}

Keywords Poverty $\cdot$ Cost of living $\cdot$ Supplemental poverty measure $\cdot$ Transportation $\cdot$ Housing costs

\section{Introduction}

Poverty measurement in the United States remains an issue of concern for applied social scientists, policy makers, and the public. The Official Poverty Measure (OPM) of the United States is often critiqued on several grounds. These critiques include the

J. Tom Mueller

tom.mueller@ou.edu

1 Department of Geography and Environmental Sustainability, University of Oklahoma, Norman, USA

2 Centre on Population and Dynamics and Department of Sociology, McGill University, Montréal, Canada

3 Kids First Chicago, Chicago, USA 
measure's (1) lack of construct validity, meaning the measure does not capture what it purports to capture; (2) its low bar for what constitutes poverty, meaning that there are many above the OPM threshold struggling to make ends meet; (3) that it only counts pre-tax wages, other sources of cash income, and cash-based government transfers as income; and (4) that it does not adjust for cost of living (Brady, 2003; Iceland, 2005; Jensen \& Ely, 2017; Ver Ploeg \& Citro, 2008). To remedy these discrepancies, in the mid-1990s, a National Academy of Sciences panel developed a set of recommendations that were ultimately used by the US Census Bureau to create the Supplemental Poverty Measure (SPM; Hutto et al., 2011; Iceland, 2005; Short, 2011; Warren et al., 2020). The SPM, as detailed below, aimed to remedy many of the methodological and conceptual concerns raised over time about the OPM. One key improvement is that the SPM adjusts for cost of living across the United States. However, the validity of the adopted adjustment remains in question.

The SPM results in higher estimates of poverty than the OPM for most population groups except those living in nonmetropolitan counties and children (Fox, 2020; Jensen \& Ely, 2017). ${ }^{1}$ The lower rates of SPM poverty for nonmetropolitan counties are attributable to the geographic adjustment within the measure (Pacas \& Rothwell, 2020). This adjustment, which is based on gross median rent, suggests that once we consider cost of living, nonmetropolitan poverty is lower than metropolitanthe opposite of what the OPM, and a large body of historical literature would suggest (Tickamyer et al., 2017; Weber et al., 2005). Unsurprisingly, there are researchers who have critiqued this approach, arguing that solely adjusting for median rent may be inappropriate because it overlooks other aspects of cost of living which may vary inversely with median rent, key among these being the assumed higher costs of transportation found in nonmetropolitan areas (Jensen \& Ely, 2017).

An additional concern, not levied in prior scholarship, relates to the higher rates of homeownership versus renting (i.e., tenure) found in nonmetropolitan areas (Barcus, 2010; Scally et al., 2018). Although the SPM does adjust poverty thresholds by tenure, the mechanism for doing so is still grounded in median rent and, thus, assumes that median rent maps well onto owner-occupied housing costs. This assumption may or may not hold due to the higher levels of homeownership found in nonmetropolitan relative to metropolitan areas (Barcus, 2010; Scally et al., 2018). Beyond critiques of the specific indicator for cost of living used, others have critiqued the operationalization of this indicator, which assigns the same adjustment to all nonmetropolitan areas within a state, smoothing over important intrastate variation (Pacas \& Rothwell, 2020).

In this study, we evaluate these critiques of the geographic adjustment in the SPM using both microdata and aggregate data from the American Community Survey. We first evaluate how well median rent compares against transportation costs and

\footnotetext{
1 In this study, we focus on nonmetropolitan vs. metropolitan counties as defined by the Office of Management and Budget (OMB). We do so because that is how the geographic adjustments in the SPM are structured. A county is considered to be in a metropolitan area if it has a core urban area of at least 50,000 people or it is connected to a core metropolitan county by at least $25 \%$ of commuting. All other counties are considered nonmetropolitan (Office of Management and Budget, 2010).
} 
tenure as a cost-of-living indicator and then assess the implementation of the costof-living adjustment as it is currently performed in the SPM.

\section{Background}

\section{Measurement of Poverty in the United States}

While we primarily focus on the SPM's geographic adjustment and test some of its underlying assumptions, it is important to first summarize the overall construction of the SPM and how it improves upon the more widely used Official Poverty Measure. The Official Poverty Measure (OPM) of the United States was developed in 1965 by Mollie Orshansky - a statistician who worked for the Social Security Administration (Iceland, 2013). Orshansky developed multiple measures of deprivation during her career including an "economy food plan" which formed the basis of the OPM used today. The economy food plan represented the minimum amount of money needed to feed a family of a given size based on household consumption data from the 1950's. To calculate a full threshold of poverty-i.e., the income required to not be in poverty-Orshansky then multiplied this minimum amount by three, as consumption data at the time reported that an average family spent about a third of their income on food (Iceland, 2013). This measure was then implemented by the Lyndon Johnson administration in 1965 as part of its "War on Poverty" for use in federal statistics. Today, the OPM still directly informs the Department of Health and Human Services Poverty Guidelines, which vary slightly from the actual OPM and are used as the criterion for eligibility in government programs like the Supplemental Nutrition Assistance Program (SNAP; ASPE, 2021; Iceland, 2013; Hutto et al., 2011).

The calculation of the OPM has received little modification since the 1960's besides being annually updated for inflation. It is calculated using a family's pre-tax income (i.e., wage earnings, social security, finance-based income), but not nearcash government transfers like SNAP (Brady, 2003), and sets separate thresholds for families based on household size and composition. This way of measuring poverty is not without its faults and has been criticized by many social scientists (Citro \& Michael, 1995; Hutto et al., 2011). First, many argue that the United States is very different than it was in 1965, and simply multiplying a "basket of goods" by three to assess the income needed to meet a basic standard of living is inadequate; with recent data showing that food now takes up a much smaller proportion of household expenses compared to other costs, specifically housing (BLS, 2021; Hutto et al., 2011). Second, the OPM uses pre-tax cash income and misconstrues the financial resources available to a family by ignoring income lost due to taxes, as well as governmental transfers like SNAP and the Earned Income Tax Credit that provide nontrivial resources to low-income families.

These serious issues of the OPM led the National Academy of Sciences to commission a study in the mid-1990s to evaluate the OPM and propose recommendations for a new measure (Citro \& Michael, 1995; Hutto et al., 2011). These recommendations were adapted into a new measure, known as the Supplemental Poverty 
Measure (SPM), released by the US Census Bureau in 2011 (Short, 2011). The SPM directly addresses these previously mentioned criticisms of the OPM and incorporates other changes deemed necessary to measure poverty accurately. Importantly, the SPM utilizes a broader definition of the family, with cohabitating partners and their children as well as foster children being considered a single-family unit (BLS, 2010). Unlike the OPM, the thresholds in the SPM are determined using a quasirelative approach (Brady, 2003; Citro \& Michael, 1995; Hutto et al., 2011). Using the Consumer Expenditure Survey, the SPM's income threshold is set at 1.2 times the mean spending of families with two parents and two children between the 30 and 36 percentile of spending on four main necessities: food, shelter, clothing, and utilities (Jensen \& Ely, 2017; BLS, 2010). The use of 1.2 times, as opposed to 1, allows for the inclusion of other necessities not captured by these four categories (Iceland, 2005; BLS, 2010). Finally, the SPM also deducts select nondiscretionary expenses from income: work-related transportation and other costs, childcare, and out-of-pocket medical expenditures (Hutto et al., 2011; BLS, 2010). The rationale for doing so is that these costs are viewed as a first priority for families and without these expenses, individuals likely could not work and, thus, would not be able to secure any income.

Overall, many scholars view the SPM as a significant improvement over the OPM (Hutto et al., 2011; Smeeding, 2016; Thiede \& Brooks, 2018; Wimer et al., 2016). Due to the stated differences in the construction of the OPM and SPM, rates of poverty both past and present differ between which measure is used (Wimer et al., 2016) — with rates of SPM poverty in 2019 being slightly higher than under the OPM (11.7\% vs. 10.5\%; Semega et al., 2020; Fox, 2020). The characteristics of families in poverty also differ between measures. For example, rates of poverty among children and their families are lower under the SPM due to the SPM's inclusion of SNAP benefits (Wimer et al., 2016; Pac et al., 2017). Finally, as noted above, poverty estimates of places, particularly metropolitan versus nonmetropolitan places, differ between the measures, and the reasons as to why have received scholarly debate and are of key importance to this study (Jensen \& Ely, 2017; Pacas \& Rothwell, 2020).

\section{The Geographic Adjustment of the SPM}

The component of the SPM that is key to this study, as well as understanding and estimating differences in metropolitan and nonmetropolitan poverty overall, is the SPM's geographic adjustment (Hutto et al., 2011; Jensen \& Ely, 2017; Pacas $\&$ Rothwell, 2020). At present, the SPM accounts for differences in cost of living across 342 metropolitan and nonmetropolitan areas in the United States (Pacas \& Rothwell, 2020). The geographic adjustment is based on a formula that accounts for the percent of residents within an area who are owners with a mortgage, owners without a mortgage, or renters, and is fundamentally grounded in the median rent of the area [see Renwick (2020) for a full discussion of this calculation]. For this study, it is important to note that for those living in metropolitan areas large enough to be identified in the Current Population Survey (CPS), their geographic 
adjustment is based on the characteristics of the metropolitan area in which they live, while for those in nonmetropolitan areas or smaller unidentified metropolitan areas, their adjustment considers the characteristics of all nonmetropolitan/unidentified metropolitan counties within their state of residence. In both instances, median rent is based on the median gross rent (rent plus utilities) of a two-bedroom unit with complete kitchen and bathroom facilities (Renwick, 2011, 2020). Data for this calculation are sourced from the relevant 5-year estimates of the American Community Survey (Bishaw, 2009). In the most basic terms, those living in places with higher median rents have a higher geographic adjustment to their poverty threshold and thus must have a higher income to not be in poverty.

Among other things, the geographic adjustment is one of the main factors than explains why poverty rates differ between metropolitan and nonmetropolitan areas under the SPM and OPM (Nolan et al., 2017; Pacas \& Rothwell, 2020). Under the OPM, poverty rates are higher in nonmetropolitan areas than in metropolitan areas (Jensen \& Ely, 2017); with poverty rates in 2018 differing by 3.5 percentage points (16.1\% vs. 12.6; Farrigan, 2020). Under the SPM the opposite is true, with nonmetropolitan poverty rates being lower than metropolitan rates by more than 1 percentage point (Pacas \& Davis, 2018). Clearly the differences in construction between the two measures changes how researchers understand geographic variation in poverty.

The use of the SPM impacts how researchers view historical differences in metropolitan and nonmetropolitan poverty. Nolan et al. (2017) find that in that 1967 the rural-urban poverty gap in the OPM stood at $9 \%$ and had declined to $2 \%$ by 2014. However, when using the SPM, they find rural poverty was $12 \%$ higher than urban poverty in 1967, and had fallen below urban poverty rates by 2014 (Nolan et al., 2017). Among other reasons, they attribute these OPM-SPM differences to a significant cost-of-living increase for urban residents over the period. It should be noted that Nolan and colleagues elected to treat areas listed as "not identified" as urban for their analysis. Pacas and Rothwell (2020) also attribute the nonmetropolitan poverty "advantage" under the SPM to the geographic adjustment. They find that the geographic adjustment decreases nonmetropolitan poverty in 2016-2018 by 5 percentage points (17.9 vs. $12.9 \%$ ) compared to estimates that use all other components of the SPM but no geographic adjustment. Further, they find that the effect of the geographic adjustment differs from state to state. For example, poverty rates in Kentucky differ by over 7.6 percentage points when comparing an SPM adjusting for cost of living in nonmetropolitan areas to one that does not, while this variation is only 0.66 percentage points in Oregon (Pacas \& Rothwell, 2020).

While many researchers believe any geographic adjustment is a marked improvement over the OPM and is needed to properly gauge poverty in the United States; its current implementation is not without criticism. Scholars of rural poverty have critiqued the geographic adjustment due to its focus on median rent (Jensen \& Ely, 2017; Pacas \& Rothwell, 2020). These critiques argue that median rent is possibly a valid measure in metropolitan areas but may not be appropriate in nonmetropolitan areas where housing may be cheap, but transportation costs are higher and owning a car is a requirement. Additionally, the variation in tenure in nonmetropolitan areas, wherein the relative share of the population renting versus owning is much lower than in metropolitan areas (Barcus, 2010; Scally et al., 2018), makes it possible that 
median rent as an indicator is not relevant to large portions of the nonmetropolitan population.

Beyond the issue of median rent as the indicator of cost of living, recent scholarship has critiqued the implementation of this adjustment, which is constrained by geographic identification within the CPS - the dataset used to generate SPM estimates (Pacas \& Rothwell, 2020). The CPS, particularly the Annual Social and Economic Supplement (ASEC), is used to generate the SPM because it is the only dataset containing all of the necessary variables for its calculation. In the CPS, people are identified as either living in one of 260 metro areas deemed large enough for identification, 35 unidentified metro areas, or one of 47 nonmetropolitan areas. In creating this adjustment, both the unidentified metro areas and the nonmetropolitan areas are pooled into single state-level geographic areas (e.g., all of the nonmetropolitan areas of a state are pooled together and all of the unidentified metro areas of a state are pooled together), which is potentially problematic given county to county heterogeneity in cost of living. Thus, even if median rent can be considered appropriate as the sole indicator of cost of living, the current implementation of the measure may be biased.

In this study we evaluate these critiques of the geographic adjustment by examining how housing costs, housing tenure, and transportation costs differ between the metropolitan and nonmetropolitan United States as a whole and how these factors vary within states. As such, we first overview the existing literature on metropolitan and nonmetropolitan differences in cost of living in order to establish an empirical and conceptual baseline for the estimates we produce.

\section{Cost of Living in Metropolitan and Nonmetropolitan Areas}

Residents of metropolitan and nonmetropolitan America differ greatly in the jobs they work, their racial and ethnic makeup, their educational attainment (Johnson \& Lichter, 2020; Slack et al., 2019; Ziliak, 2018), and as previously mentioned, their overall level of poverty and affluence (Nolan et al., 2017; Thiede et al., 2018; Weber $\&$ Miller, 2017). On the surface, these demographic and economic differences likely reflect and produce differences in cost of living. In fact, in response to the initial National Academy of Sciences recommendations for cost-of-living adjustments in measures of poverty, Nord (2000) assessed cost of living between metropolitan and nonmetropolitan areas as it related to food security and found that nonmetropolitan residents do generally have lower costs of living than their metropolitan counterparts. Similarly, the Bureau of Economic Analysis' Regional Price Parity data for 2020 shows that the nonmetropolitan portions of the vast majority of states have a lower price level than their metropolitan counterpart, whether looking at the overall index or rent specifically (Bureau of Economic Analysis, 2021). That said, other research suggests that these differences may be much smaller than believed by the general public and researchers (Ghelfi, 1988; Zimmerman et al., 2008). One recent study finds that outside of the largest metro areas, the so-called "big-mac" index-a measure often used to capture local variation in food prices-has little geographic variation (Loveridge \& Paredas, 2018). However, while overall cost of living may 
vary less than many assume, that does not mean that specific housing and transportation costs do not differ across space-especially since housing and transportation costs are often viewed as directly in conflict (Lipman, 2006).

Research shows that housing costs are influenced by place-level characteristics such as local amenities, distance to major centers, and housing market competition (Gyourko, 2009; Pattillo, 2013). In line with this, the 2016 American Community Survey (ACS) - a regularly occurring national survey of the United States population which replaced the long form decennial census and began in 2005-shows that in the ten largest metro areas, housing costs averaged around $\$ 1300$ per month compared to $\$ 700$ in small metropolitan areas and $\$ 650$ for nonmetropolitan counties. This suggests that while there are clear differences between the largest metropolitan areas and the rest of the country, there is limited variation in average housing costs between most metropolitan and nonmetropolitan counties (Harvard, 2018). Brooks (2022) finds similar results, in that median housing costs in large metros in 2016 were $\$ 1250$ dollars compared to $\$ 688$ for nonmetro counties adjacent to metro areas and $\$ 607$ dollars for remote nonmetro counties. Although there may be limited variation between national averages, when looking sub-nationally, Holly et al. (2010) show that there is significant variation at the state and regional levels. Further, work from Pacas and Rothwell (2020) suggests there is not only significant variation in housing costs between states, but also within states-particularly between nonmetropolitan counties. Overall, this variation in housing costs remains understudied and is a subject of our analysis. ${ }^{2}$

Regarding housing tenure-whether a household owns or rents their housingthere is a general notion that renting is dominant in metropolitan areas while homeownership is prominent in nonmetropolitan areas (Scally et al., 2018). One study finds that in 2006, 67\% of nonmetropolitan households were owners compared to $48.6 \%$ of central city households, but that homeownership was most prevalent in the suburbs at $68.1 \%$ (Barcas, 2010). More recent data show that in mostly rural counties (counties with over $50 \%$ of census tracts designated as rural), homeownership rates were at $74.4 \%$ compared to mostly urban counties at $68.2 \%$ (Mazur, 2016). This higher prevalence of homeownership in nonmetropolitan America may be attributed to land availability (Barcus, 2010; Marx, 2010), as well as a higher proportion of elderly individuals who are the most likely age group to own a home (Glasglow \& Brown, 2012; Vega \& Wallace, 2016). However, with the growth of rural retirement destinations and natural amenity-related migration, rural renting may be on the rise in order to accommodate seasonal housing and so-called "snowbirds" (Hall, 2010; Nelson \& Hines, 2018; Winkler et al., 2012).

\footnotetext{
${ }^{2}$ It should be noted that the SPM and the cited studies use gross housing as their measure of housing costs. Gross housing costs refer to a household's contract rent or mortgage plus utilities, fees, and insurance (Herbert et al., 2018), which are relevant to this study due documented rural-urban variation in household utility costs. Nonmetropolitan households spend on average $4.4 \%$ of income (\$1905) on electricity, gas, and other energy costs compared to $3.1 \%(\$ 11,812)$ for metropolitan households (Ross et al., 2018). These higher proportional and absolute costs may make up for nonmetropolitan households initially lower contract rent.
} 
A final component of cost of living important to this study is transportation time and costs, as these factors are important component of household budgets and are often regarded as inversely related to housing costs (Hamidi et al., 2016; Lipman, 2006). Although variable by gender, race, and ethnicity, scholarship has historically shown low-wage workers tend to have shorter distance commutes than high-wage earners within the metropolitan context, suggesting that transportation costs may play a minimal role in cost of living for low-income families relative to housing costs (Kim et al., 2012; McLafferty \& Preston, 2019). However, it should be noted that recent work suggests that this pattern is changing as urban cores are increasingly gentrified and dominated by high-wage earners, generating an increasingly large spatial mismatch-wherein affordable housing and low-wage work are located far from one another (McLafferty \& Preston, 2019). Thus, it is increasingly the case that low-income individuals in metropolitan areas have longer commutes than highwage workers, largely as a result of rising housing costs near the majority of jobs.

Outside of the metropolitan context, some scholars of rural poverty criticize the SPM for not including transportation costs (Jensen \& Ely, 2017), and others argue that transportation is an underappreciated determinant of cost of living in rural areas (Duncan et al., 2002; Needles Fletcher et al., 2010). Because of a lack of data, statistics on rural-urban variation in transportation costs, especially at any sub-nationally representative level - are difficult to come by. For example, data on rural-urban variation in gasoline prices are not readily available, with public gasoline price data only available at the state level (EIA, 2021). Due to this, in our analysis, we use commuting time as a proxy for transportation costs. This proxy relies on the argument that spending more time commuting, particularly by car, imposes greater real costs to households in the form of gasoline, wear and tear, and time that could be spent earning income. From the outset, we should note that this is a decision which imposes limitations on the generalizability of our results as they relate to the broad cost of transportation for two reasons: (1) commuting time is unlikely to have a oneto-one relationship with commuting costs, and (2) commuting is not the only way households spend money on transportation. However, it is the best proxy available given current data limitations.

The evidence for differences in commuting time and form between metropolitan and nonmetropolitan areas remains unclear. In 2017, the Census Bureau reported that the longest average commuting times are experienced by workers who commute within large metropolitan areas, or from a small metropolitan area to a large metropolitan area (U.S. Census Bureau, 2017). However, the shortest commuting times are generally found among those in smaller metropolitan areas (U.S. Census Bureau, 2017). In terms of commuting mode, Fan et al. (2017) find that rural workers are about half as likely as urban workers to commute by walking, biking, or public transit but that well over $90 \%$ of workers in both areas still drive to work. Further, driving to work alone (e.g., not car pooling) only varies slightly across the rural-urban continuum, with $80 \%$ of workers in metropolitan counties commuting this way compared to $76 \%$ of the those in remote small nonmetropolitan counties (Henning-Smith et al., 2018). Thus, although many have argued for a nonmetropolitan transportation disadvantage, the actual evidence remains mixed. Ultimately, variation in commuting patterns between metropolitan and nonmetropolitan areas, and how those 
patterns relate to housing costs remains an open empirical question to which we will now turn.

\section{Methods}

In what follows, we evaluate these critiques of the geographic adjustment within the SPM by first contrasting variation between metropolitan, unidentified, and nonmetropolitan areas along the dimensions of housing costs, tenure, and commuting time-overall and by car specifically. Second, we assess variation in housing costs (i.e., the primary variable used in the geographic adjustment) within nonmetropolitan areas of states. To improve sample size and facilitate comparison between aggregate county-level data and microdata, we rely on the American Community Survey and not the Current Population Survey. As previously noted, for our analysis of transportation, we focus on commuting time and employ it as a proxy of transportation costs. To increase the validity of this approach, we conduct our analysis for all commuters, as well as those who commute by car. To meet our second objective, we then explore the variability of gross median two-bedroom rent across nonmetropolitan counties within states to explore the possible issues with the current implementation of the geographic adjustment used in the calculation of the SPM.

\section{Data}

We extracted data from the American Community Survey (ACS) from two different IPUMS databases. Microdata, which do not provide information on county of residence but do provide SPM geographies-meaning metropolitan, nonmetropolitan, and unidentified-were extracted from IPUMS-USA (Ruggles et al., 2021), and aggregate county-level data were extracted from IPUMS-NHGIS (Manson et al., 2021). IPUMS-USA is a public access harmonized database of ACS microdata and IPUMS-NHGIS is the National Historic Geographic Information System-a database of harmonized US Census Bureau data aggregated to numerous levels of spatial resolution including the tract, county, state, and nation. To ensure complete coverage, comparability, and reliable estimates, we extracted five-year estimates from 2014 to 2018 for both microdata and aggregate data.

\section{Variables}

The variables used in this analysis were selected to capture the dimensions of cost of living previously discussed. For housing, we analyze tenure and housing costs. Tenure was captured by estimating the percent of housing in an area that was either owner occupied with a mortgage, owner occupied without a mortgage, or renter occupied. To keep our analysis in alignment with the SPM, we combined renter occupied but not paying cash rent with owner occupied without a mortgage (Fox \& Burns, 2021). Housing costs were captured via median monthly owner-occupied housing costs (with and without mortgage), median 
gross rent, and median gross two-bedroom rent. We include both as a means of comparing overall variation in gross rent with the specific metric used in the SPM.

Transportation was assessed by commuting form and commuting time. Commuting form was assessed in relation to the percent of workers over 16 in an area commuting by either car, truck, or van; public transit; or walking. Commuting time was captured via reported time of commute in minutes reported by workers over 16. This was aggregated as both a mean and median for all commuters and just those commuting via car-defined in the ACS as those who reported auto, truck, or van as their primary means of transportation to work in the week preceding the survey.

An important dimension for our analysis was the geographic coding of microdata. We classified microdata cases as either living in a metropolitan area, a nonmetropolitan area, or an unidentified area. We use these three categories to approximate the geographies actually used in the SPM when calculating the measure via the CPS. Due to concerns of privacy disclosure, the Census Bureau does not reveal the specific metropolitan area of a respondent in the CPS when the area is below a certain size or number of respondents. This results in the CPS having three categories: identified metropolitan areas, unidentified metropolitan areas, and nonmetropolitan area. The level of identification is different in the case of ACS microdata. Metropolitan status in not provided by the Census for ACS microdata. Instead, IPUMS-USA generates this classification using the smallest level of geography provided, Public Use Microdata Areas (PUMAs). PUMAs are apolitical geographic units which follow either county or census tract boundaries and contain no less than 100,000 people (U.S. Census Bureau, 2021). If a PUMA is entirely metropolitan, it is treated as metropolitan, and if a PUMA is entirely nonmetropolitan, it is treated as nonmetropolitan. In the case of a PUMA straddling a metropolitan and nonmetropolitan area, the area is coded as mixed or unidentified. Although this does represent a limitation in regard to comparing these results to the exact geographies used within the CPS, it is the best available approximation using large-scale publicly available microdata. Further, given the ability of these unidentified cases to impact aggregate population statistics, it is essential that we report them here.

Several other variables were important for the analytic approach described below. First, aggregate county-level data from NHGIS were merged with ERS Rural Urban Continuum Codes (RUCC) to clearly establish the metropolitan/ nonmetropolitan status of a county (USDA-ERS, 2013). The RUCC classification scheme has nine levels. The first three include metropolitan counties and are separated by the overall population of the metropolitan area county is a part of. The remaining six are comprised of nonmetropolitan counties separated by their urban population size, as well as whether or not they are adjacent to a metropolitan area. Second, we include state for our state adjustments. Third, because our analysis is ultimately interested in poverty determination, we analyze both the full population and the low-income population by defining low income as anyone living in a household whose income is less than $150 \%$ of the appropriate OPM threshold. 


\section{Analytic Approach}

Our analysis proceeds in two distinct steps. First, we use ACS microdata to estimate cost-of-living variation for SPM geographies. SPM geographies refers to the geographies we use in the ACS microdata to approximate the geographies used in the SPM to adjust for cost of living. This includes metropolitan, nonmetropolitan, and unidentified. To adjust for state-level variation, we estimate each outcome using OLS regression with state-fixed effects and cluster-robust standard errors on the state. This approach allows us to generate summary statistics for each level of SPM geography across the United States while still approximating the state-level adjustments we see in the SPM. Since the SPM generates state-specific thresholds by the three levels of SPM geography, it is necessary for us to estimate and compare some form of state-level adjustment such as the described fixed effects. Without a comparative adjustment like this, the results would be less comparable to the actual estimation of the SPM via the CPS. These adjusted rates were calculated using margins within Stata 16 for percentage variables and means. In the case of adjusted medians, individual level predictions of each outcome for each case were first estimated via regression. This is equivalent to assigning each combination of SPM geography and state a shared predicted value for each outcome. From this, the adjusted medians were calculated in the same manner as the unadjusted medians by collapsing a median of these predicted values using the relevant survey weight. This procedure was followed for all housing and transportation outcomes. We first conduct this analysis for the entire population and then for just the low-income population. Finally, because of the strong influence the ten largest metropolitan areas have on aggregate data (Harvard, 2018), we also estimate all statistics with these ten metropolitan areas removed. ${ }^{3}$ Due to a lack of variation, we do not report this set of results in tabular form and simply describe the results narratively.

After this initial evaluation of indicators between metropolitan and nonmetropolitan areas within the United States, we then use aggregate county-level data to assess the level of variation between nonmetropolitan counties in each state. In this portion of the analysis, we focus exclusively on median gross two-bedroom rent. The analysis is descriptive and is a series of box and whisker plots by different levels of rurality moving from the SPM geography, which combines all nonmetropolitan counties in a state, to a dichotomous classification of nonmetropolitan counties by metropolitan adjacency, to a full six-level breakout of nonmetropolitan RUCC categories. To facilitate a feasible analysis, we limit our more in-depth analysis to case studies of three states that contain the full set of RUCC categories and a large number of counties: North Carolina, Georgia, and Kansas. Due to the constraints of aggregate data, we cannot focus on the

\footnotetext{
3 In descending order, the ten largest metropolitan areas which were dropped include New York-NewarkJersey City, NY-NJ-PA; Los Angeles-Long Beach-Anaheim, CA; Chicago-Naperville-Elgin, IL-IN-WI; Dallas-Fort Worth-Arlington, TX; Houston-The Woodlands-Sugar Land, TX; Philadelphia-CamdenWilmington, PA-NJ-DE; Washington-Arlington-Alexandria, D.C.-VA-MD-WV; Atlanta-Sandy SpringsRoswell, GA; Miami-Fort Lauderdale-West Palm Beach, FL; and Boston-Cambridge-Newton, MA-NH.
} 
Table 1 Housing tenure and cost by metropolitan status

\begin{tabular}{lccc}
\hline Statistic & $\begin{array}{l}\text { Metropolitan } \\
(79.79 \%)\end{array}$ & $\begin{array}{l}\text { Nonmetropolitan } \\
(8.22 \%)\end{array}$ & $\begin{array}{l}\text { Unidentified } \\
(12.00 \%)\end{array}$ \\
\hline Tenure & & & 37.68 \\
Owner occupied with mortgage (\%) & 40.81 & 35.63 & 34.99 \\
Owner occupied without mortgage $(\%)^{\mathrm{a}}$ & 22.53 & 37.42 & 27.33 \\
Renter occupied (\%) & 36.65 & 26.95 & 1311.59 \\
Housing costs & & & 438.74 \\
Median monthly owner costs with mortgage & 1849.67 & 1165.62 & 751.91 \\
Median monthly owner costs without mortgage & 630.23 & 425.80 & 723.31 \\
Median gross rent & 1183.39 & 700.38 & 658.55 \\
Median gross rent-two bedrooms & 1129.08 & & \\
\hline
\end{tabular}

${ }^{a}$ Includes renter not paying cash rent. This is due to the groupings used in the calculation of the SPM, wherein Owner Occupied without Mortgage also includes renters paying no cash rent

Estimates adjusted for state-level factors via state-fixed effects

low-income population in the second portion of the analysis and instead only focus on the overall population.

\section{Results}

\section{Variation Between Metropolitan and Nonmetropolitan Tenure, Transportation, and Housing Costs}

The results for housing across the entire population are presented in Table 1. We find that home ownership with a mortgage is more prevalent for metropolitan America than nonmetropolitan. However, we find that home ownership without a mortgage is much more likely in nonmetropolitan areas than metropolitan. Turning to housing costs, we find that housing costs are cheaper for nonmetropolitan households whether or not they own their home and whether or not they have a mortgage. Although generally falling between nonmetropolitan and metropolitan, unidentified areas were more similar to nonmetropolitan than metropolitan areas for all outcomes.

Our findings for commuting form and time do not support the notion that nonmetropolitan people spend significantly more time commuting than their metropolitan counterparts. In terms of form, we do find that nonmetropolitan adults are more likely to commute by car and less likely to take public transit, but the differences are very slight. When we turn to commuting time, we find metropolitan workers spend more time commuting both overall and when only looking at car commuters (Table 2). 
Table 2 Transportation form and time by metropolitan status

\begin{tabular}{llcc}
\hline Statistic & $\begin{array}{l}\text { Metropolitan } \\
(79.79 \%)\end{array}$ & $\begin{array}{l}\text { Nonmetropolitan } \\
(8.22 \%)\end{array}$ & $\begin{array}{l}\text { Unidentified } \\
(12.00 \%)\end{array}$ \\
\hline Commuting form & & & 87.10 \\
Car (\%) & 83.06 & 2.38 & 2.06 \\
Public transit (\%) & 5.56 & 3.09 & 2.62 \\
Walk (\%) & 2.59 & & 24.05 \\
Commuting time & & 22.69 & 22.39 \\
Average time (minutes) & 25.06 & 20.71 & 25.56 \\
Median time (minutes) & 25.38 & 24.19 & 24.76 \\
Average time for cars (minutes) & 25.78 & 23.02 & \\
Median time for cars (minutes) & 26.35 & & \\
\hline
\end{tabular}

Estimates adjusted for state-level factors via state-fixed effects

Table 3 Housing tenure and costs by metropolitan status-low income

\begin{tabular}{lccc}
\hline Statistic & $\begin{array}{l}\text { Metropolitan } \\
(76.05 \%)\end{array}$ & $\begin{array}{l}\text { Nonmetropolitan } \\
(10.07 \%)\end{array}$ & $\begin{array}{l}\text { Unidentified } \\
(13.88 \%)\end{array}$ \\
\hline Tenure & & & 16.83 \\
Owner occupied with mortgage (\%) & 15.81 & 16.81 & 34.69 \\
Owner occupied without mortgage $(\%)^{\mathrm{a}}$ & 21.16 & 37.13 & 48.48 \\
Renter occupied (\%) & 63.04 & 46.06 & 1030.62 \\
Housing costs & 1345.62 & 929.48 & 351.74 \\
Median monthly owner costs with mortgage & 485.97 & 342.34 & 674.79 \\
Median monthly owner costs without mortgage & 928.00 & 635.34 & 663.98 \\
Median gross rent & 926.92 & 607.54 & $150 \%$ \\
Median gross rent-two bedrooms & & & \\
\hline
\end{tabular}

Low-income population includes anyone living in a household whose income is less than $150 \%$ of the appropriate official poverty measure threshold

${ }^{a}$ Includes renter not paying cash rent. This is due to the groupings used in the calculation of the SPM, wherein Owner Occupied without Mortgage also includes renters paying no cash rent

Estimates adjusted for state-level factors via state-fixed effects

\section{Low-Income Comparison}

Because the rationale for our analysis is anchored in the geographic adjustment of the SPM, we also conduct our analysis on just the low-income population. When we do, the differences between nonmetropolitan and metropolitan housing follow a similar pattern (Table 3). The tenure difference is larger among the low income, with low-income nonmetropolitan households being much more likely to own their home without a mortgage. However, the share owning their home with a mortgage was very similar between nonmetropolitan and metropolitan areas. Contrastingly, the housing cost discrepancy is smaller among the low-income population, with 
Table 4 Transportation form and time by metropolitan status-low income

\begin{tabular}{lccc}
\hline Statistic & Metropolitan & Nonmetropolitan & Unidentified \\
\hline Commuting form & & & \\
Car (\%) & 74.02 & 79.36 & 79.64 \\
Public transit (\%) & 7.97 & 2.66 & 2.77 \\
Walk (\%) & 7.23 & 6.89 & 6.86 \\
Commuting time & & & \\
Average time (minutes) & 22.29 & 19.46 & 19.94 \\
Median time (minutes) & 22.32 & 17.77 & 18.91 \\
Average time for cars (minutes) & 22.92 & 21.44 & 21.85 \\
Median time for cars (minutes) & 23.31 & 20.17 & 21.12 \\
\hline
\end{tabular}

Low-income population includes anyone living in a household whose income is less than $150 \%$ of the appropriate official poverty measure threshold

metropolitan households still spending more, but not quite as much more as we saw in the overall population. Again, residents of unidentified areas appeared to be inbetween the two groups but were more akin to nonmetropolitan residents.

When looking at transportation, we again find similar patterns. Nonmetropolitan workers are more likely to commute by car, and metropolitan workers spend more time commuting both overall and among only car commuters (Table 4).

\section{Excluding the Ten Largest Metropolitan Areas}

When we exclude the ten largest metropolitan areas as reported by the 2014-2018 ACS five-year estimates, our results-which include the entire population, not just the low-income population-were functionally the same. For housing, we still find the same patterns as in our analysis of the entire country. However, it should be noted that many of the differences, particularly related to housing costs, narrowed when the ten largest metropolitan areas were excluded. We find similar results for commuting, with all trends remaining the same and differences narrowing between metropolitan and nonmetropolitan areas when the largest metropolitan areas are removed.

\section{Summary}

Our findings for cost of living between nonmetropolitan and metropolitan America suggest that, if we look to commuting time as a proxy for general transportation costs, nonmetropolitan people seem unlikely to be spending more than metropolitan people on transportation. Commuting, the most regular and costly form of transportation people engage in, generally takes longer, and thus, we argue is likely to cost more, in metropolitan areas. However, it is important to note that other forms of transportation such as grocery store and doctor visits remain uncaptured in the present analysis. Regarding tenure, the pattern of housing costs does not appear to vary across tenure types between nonmetropolitan and metropolitan areas, refuting 


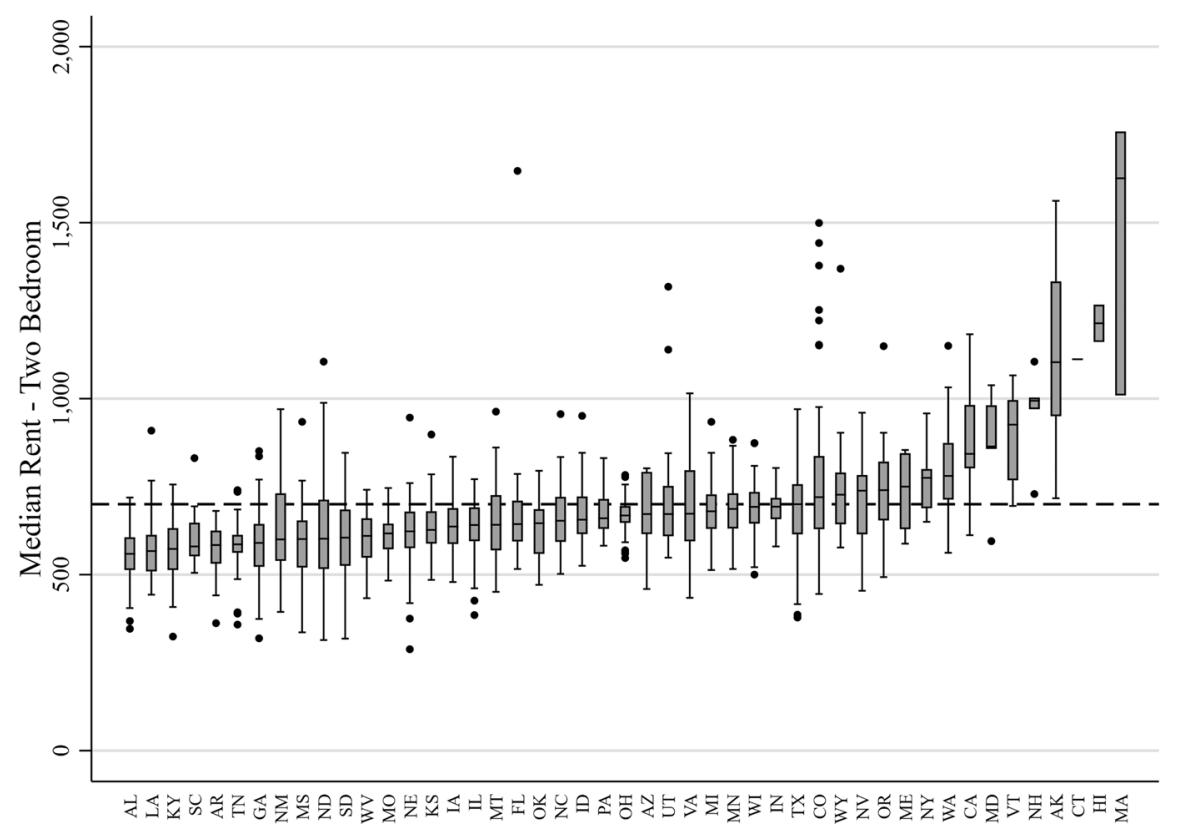

Fig. 1 Box and whisker plot of median two-bedroom rent in nonmetropolitan counties by state. Dashed line is median nonmetropolitan two-bedroom rent nationally as reported by ACS microdata

our initial critique. This suggests that even though home ownership without a mortgage is higher in nonmetropolitan areas, median gross rent likely captures this variation. Given the presented lack of evidence suggesting a discrepancy in the usage of median gross rent as a proxy for cost-of-living variation, it appears that median gross rent is likely an appropriate indicator for cost-of-living differences between metropolitan and nonmetropolitan areas in the United States. That said, this does not mean that the adjustment for this indicator in the SPM is appropriate as it is currently applied.

\section{Variation in Housing Costs Between Nonmetropolitan Areas in the Same State}

The SPM pools all nonmetropolitan counties within a state and assigns a single geographic adjustment to these counties. There is reason to believe that this approach is too coarse and biases thresholds of the SPM in nonmetropolitan America (Pacas \& Rothwell, 2020). To assess this, we now use aggregate census data to look at variation between nonmetropolitan counties within the same state.

Figure 1 presents the distribution of median gross two-bedroom rent for nonmetropolitan counties in all 47 US states with nonmetropolitan counties. The dashed line is the national nonmetropolitan median gross two-bedroom rent as determined via ACS microdata. As can be seen, there is remarkable variation within states. Many states have a range of nonmetropolitan median rents spanning well over $\$ 500$. 

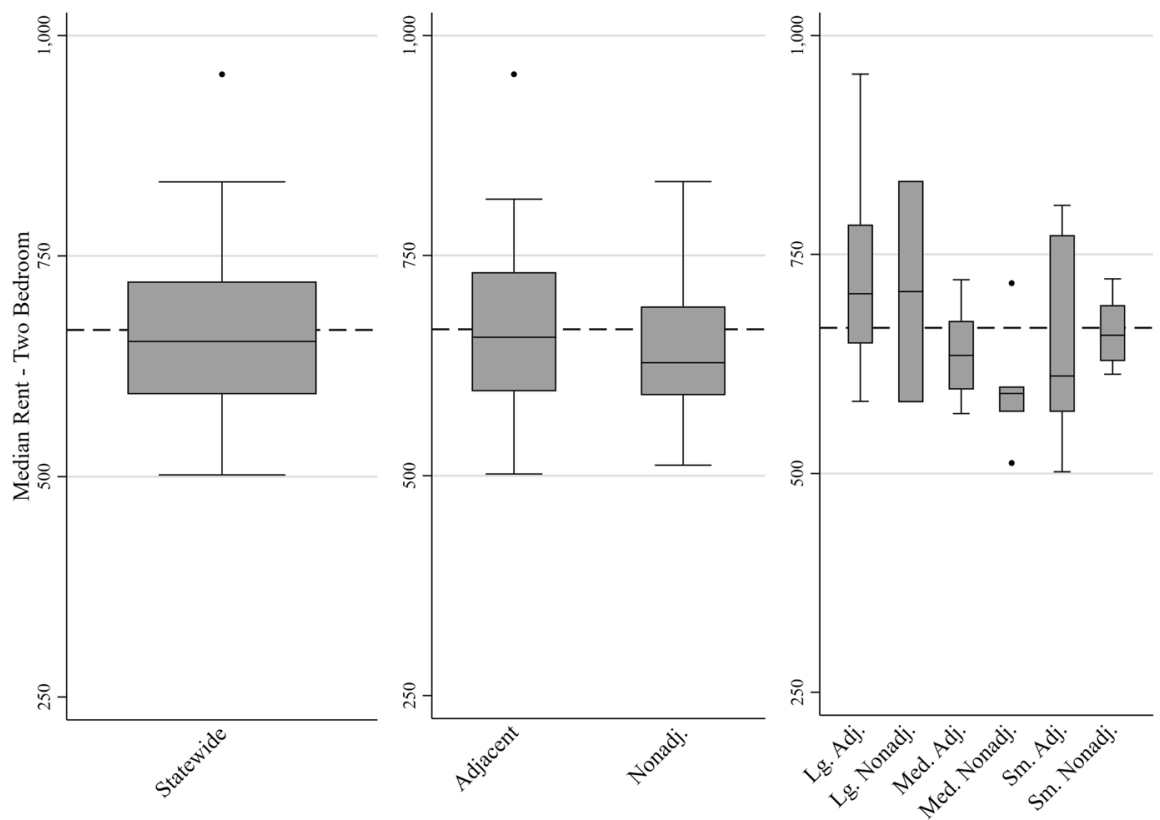

Fig. 2 Box and whisker plot of median rent in North Carolina nonmetropolitan counties by metropolitan adjacency and RUCC. Dashed line is median nonmetropolitan two-bedroom rent for North Carolina as reported by ACS microdata

Although how much variation is "too much" is ultimately subjective, from this alone, it appears assigning a single nonmetropolitan adjustment is likely inappropriate. However, it is unclear what an appropriate solution may be. Although a countyspecific adjustment would be desirable, it is unlikely nonmetropolitan microdata will have county of residence identified by the U.S. Census Bureau any time soon. Thus, a county-specific SPM adjustment is exceedingly unlikely. What may be possible is other nonmetropolitan categorizations beyond the current SPM geography that, while coarse, still provide a more useful level of detail. To assess two options, we look at three states-North Carolina, Kansas, and Georgia - by two different metropolitan and nonmetropolitan breakdowns.

Figures 2, 3, and 4 display the variation of within-state county-level median gross two-bedroom rent for our three case states by overall, metropolitan adjacency, and full RUCC. The middle panel of each figure proposes an adjustment based on whether or not a nonmetropolitan county is adjacent to a metropolitan area, with the expectation that adjacency would raise median rent (Brooks, 2022). As we can see, this is generally true. In all three states, the nonmetropolitan adjacent counties have slightly higher median rents than the nonmetropolitan nonadjacent counties. The dashed line is the state-specific nonmetropolitan median rent as determined by ACS microdata. Although the variation between nonmetropolitan counties appears like it may have been reduced using this categorization, the variation is still quite large and in the case of adjacent counties in Georgia, it actually grew. 

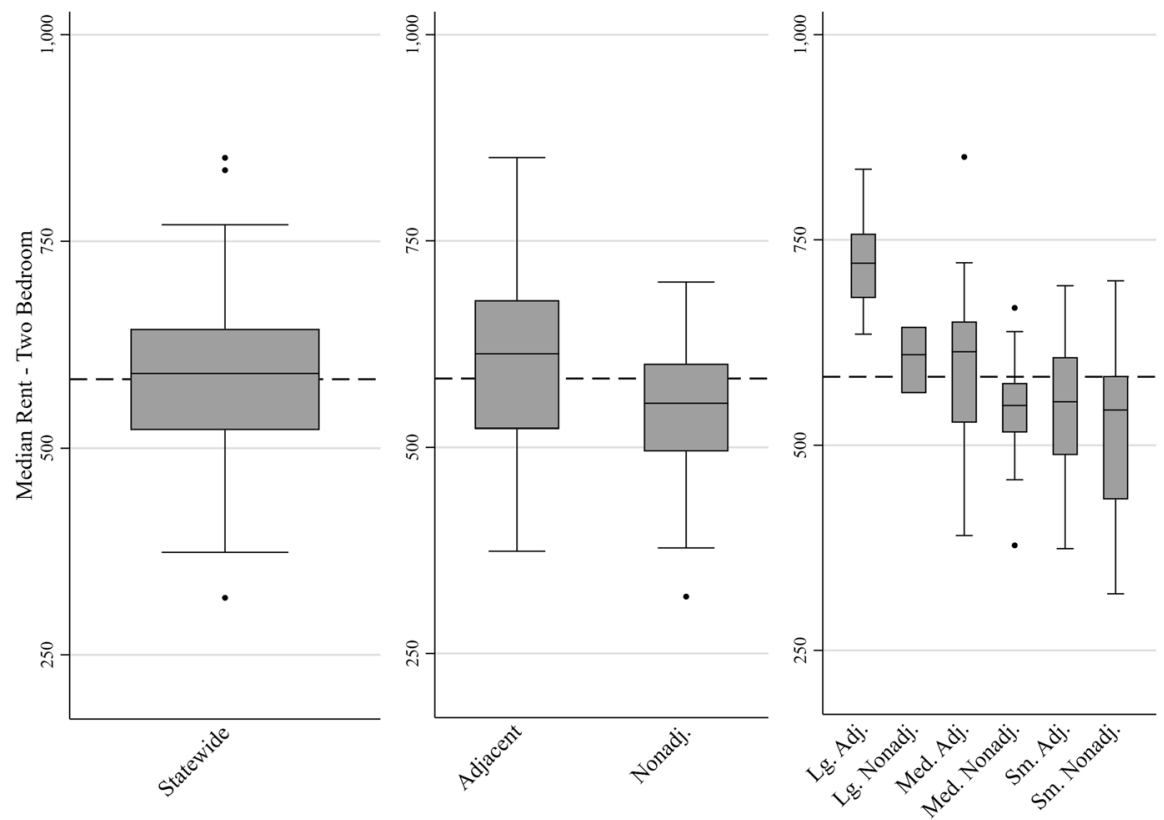

Fig. 3 Box and whisker plot of median rent in Georgia nonmetropolitan counties by metropolitan adjacency and RUCC. Dashed line is median nonmetropolitan two-bedroom rent for Georgia as reported by ACS microdata

To test the feasibility of a more-precise categorization, in the right panel of each figure, we break out median two-bedroom gross rent by full RUCC classification. As we can see, this has the effect of reducing the variation considerably for at least some of the categories. Particularly in Kansas, we see that each category except for small nonadjacent counties has lower variation than the coarser categories presented prior. That said, variation is still considerable for some RUCC levels in North Carolina, indicating that although this approach might give better adjustments, it will still likely be less appropriate than a full county-specific adjustment.

\section{Discussion}

In this study, we have analyzed cost-of-living variation between metropolitan and nonmetropolitan America, and within nonmetropolitan portions of states. We have expanded beyond prior scholarship by assessing the differences in housing costs, housing tenure, commuting time, and commuting form between metropolitan and nonmetropolitan America. We have done so as a way of assessing the assumptions and choices which exist within the geographic adjustment of the Supplemental Poverty Measure. In short, we find that the indicator of cost of living currently used in the SPM-median gross rent-appears to be appropriate when looking at variation between housing costs, commuting form, and 

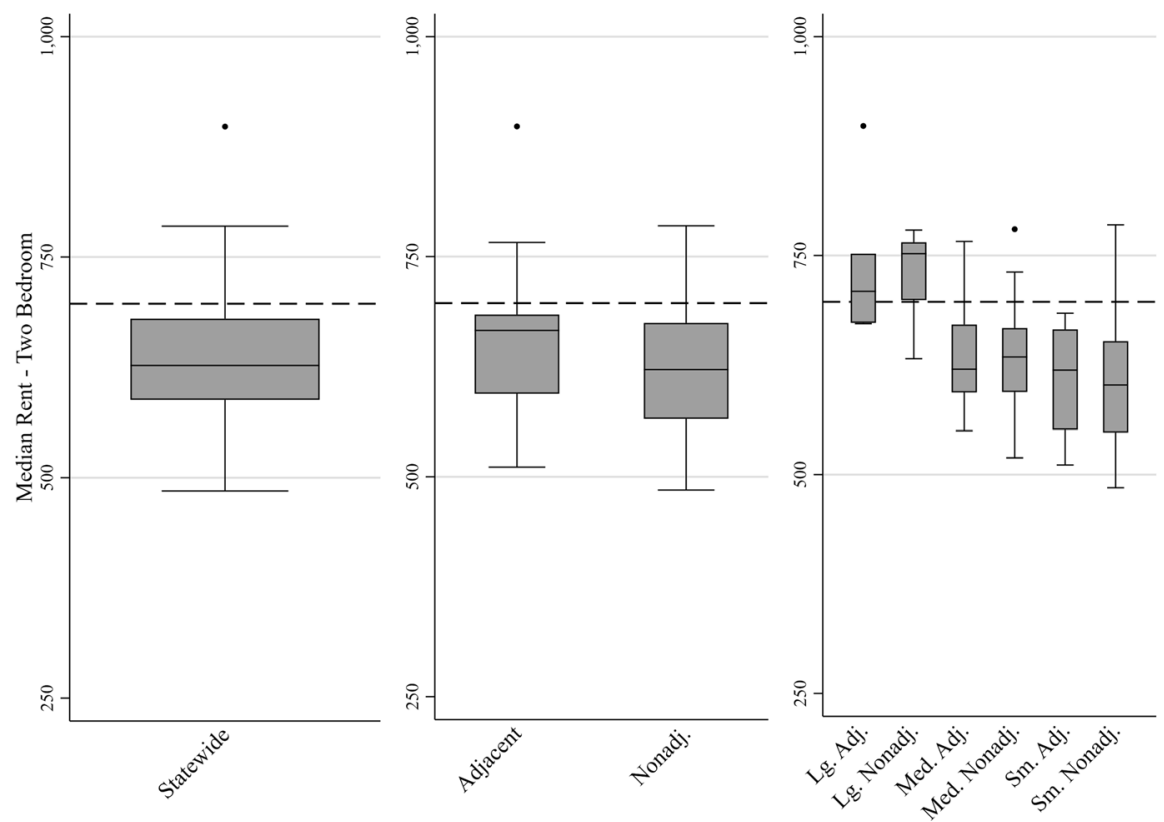

Fig. 4 Box and whisker plot of median rent in Kansas nonmetropolitan counties by metropolitan adjacency and RUCC. Dashed line is median nonmetropolitan two-bedroom rent for Kansas as reported by ACS microdata

commuting time between metropolitan and nonmetropolitan areas, but the implementation of the cost-of-living adjustment is likely introducing bias in a direction we cannot discern. The practice of assigning a single nonmetropolitan geographic adjustment for each state mutes the sizeable variation in median rents that we see between nonmetropolitan counties within each state. Similar to Pacas and Rothwell (2020), we find this practice, which is largely an artifact of the level of geographic identification provided through the Current Population Survey, appears in need of revision. We then further expanded on existing research by considering two alternative approaches to dividing rural America for a more-precise geographic adjustment.

Based on our analysis, a potential solution to improve the adjustment is to separate the currently pooled nonmetropolitan groupings within each state by some other degree of rurality. In this study, we have considered two, metropolitan adjacency and full RUCC categories. Although it appears RUCC may be a plausible direction for this adjustment to go in the future, it is clear that this approach would still be considerably less precise than a more robust county-specific adjustment. Regardless of the method, any change to the current method requires increasing the geographic precision either within the public-use files of the Current Population Survey or within census calculations of SPM thresholds - as neither metropolitan adjacency nor full RUCC are provided in public-use files. These improvements would not be without costs, particularly the given current fears and new practices related to privacy 
disclosure (Mueller \& Santos-Lozada, 2022). That said, there is likely a balance that can be struck to ensure accurate estimates of nonmetropolitan SPM.

That we find no evidence of longer commutes for those living in nonmetropolitan areas, even when focusing on just car commuters, tempers concerns raised by Jensen and Ely (2017) related to higher transportation costs in nonmetropolitan areas. Although many assume an inverse relationship between nonmetropolitan status and transportation costs, when using commuting time as a proxy for these costs, this was not supported by our analysis. While nonmetropolitan workers were more likely to rely on a car for their commute, in general, their time spent commuting was less than metropolitan workers. This does not mean that there are not likely some costs that are higher in nonmetropolitan areas relative to metropolitan areas, nor does it mean that we are fully capturing transportation costs - commuting mode and time are not the only dimensions of transportation-but what it does mean is that from our analysis and existing literature it does not seem that those differences would be enough to offset the utility of median rent as an appropriate indicator, particularly considering the tenure adjustments already made in calculating SPM thresholds.

To be clear, this evidence against the notion of a nonmetropolitan commuting disadvantage does not suggest that there is not a spatial mismatch between affordable housing and low-wage work within metropolitan or nonmetropolitan areas. This mismatch has recently been clearly documented by McLafferty and Preston (2019). Those who work low-wage jobs in metropolitan areas often have very long commutes-even if they are of short distance. Our analysis adopts the assumption used in the SPM that metropolitan and nonmetropolitan are a reasonable scale for geographic adjustment. Based on work highlighting the variation between costs of living just within the New York City region, it is clear that cost of living is not just variable between metropolitan areas but is quite variable within metropolitan areas (McLafferty \& Preston, 2019; Wong et al., 2020). Beyond metropolitan areas, counties in the United States can be quite large and have varying degrees of rurality not captured purely through population size and adjacency to urban areas. As such, it is equally likely that cost of living varies dramatically within nonmetropolitan counties. This within-area variation is currently ignored by the geographic adjustment in the SPM and likely warrants further attention from scholars.

In sum, there do not appear to be major discrepancies between transportation, tenure, or housing costs as potential components of cost-of-living differences between nonmetropolitan and metropolitan America, either within the overall population or just the low-income population. However, the implementation of the current cost-of-living adjustment likely poses significant issues for estimating nonmetropolitan SPM due to the variation observed between nonmetropolitan counties within the same state. This matters not only for measurement, but also for policy due to the increasingly common role of the SPM in policy evaluation. For example, the poverty-alleviating impacts of the temporary child tax credit during the COVID-19 pandemic were evaluated via the SPM by both the Urban Institute and the Columbia Poverty Center (Acs \& Werner, 2021; Parolin \& Curran, 2021; Parolin et al., 2022), and the US Census Bureau relied upon the SPM when evaluating the impact of COVID-19-related stimulus payments (Burns et al., 2021). If the success of povertyalleviation policy in nonmetropolitan areas is evaluated using the current geographic 
adjustment, it is likely that evaluation results will be biased. Due to the wide variation in nonmetropolitan median rent within states, the direction of this bias is likely variable but currently unable to be assessed.

Future efforts to improve our understanding of poverty across the United States should direct their attention toward resolving this issue of implementation to help improve the accuracy of poverty measurement and the effectiveness of poverty-alleviation policy. Although generating full county-specific adjustments is clearly the most prudent approach going forward, this seems an unlikely outcome in the near future due to concerns of disclosure avoidance. At present, the only way to assess whether or not accounting for intrastate variation would change SPM estimates is through the use of restricted data housed within Federal Statistical Research Data Centers - a system of data centers outside of the reach of the vast majority of applied demographers. Thus, expanding the official SPM adjustments to at least consider metropolitan adjacency or full RUCC categories appears a valuable first step.

Funding No funding to disclose.

Data Availability All data will be made publicly available on the Open Science Framework prior to publication.

Code Availability All code will be made publicly available on the Open Science Framework prior to publication.

\section{Declarations}

Conflict of interest None to disclose.

\section{References}

Acs, G., \& Werner, K. (2021). How a permanent expansion of the child tax credit could affect poverty. Urban Institute. Retrieved January 26, 2021 from https://www.urban.org/sites/default/files/publication/104626/how-a-permanent-expansion-of-the-child-tax-credit-could-affect-poverty.pdf

Assistant Secretary for Planning and Evaluation (ASPE). (2021). Frequently asked questions related to the poverty guidelines and poverty. Retrieved from https://aspe.hhs.gov/topics/poverty-economicmobility/poverty-guidelines/frequently-asked-questions-related-poverty-guidelines-poverty

Barcus, H. R. (2010). Heterogeneity of rural housing markets. In D. Marcouiller, M. Lapping, \& O. Furuseth (Eds.), Rural housing, exurbanization, and amenity-driven development: Contrasting the "Haves" and the "Have Nots." Taylor \& Francis.

Bishaw, A. (2009). Adjusting poverty thresholds based on differences in housing cost: Application of American Community Survey. U.S. Census Bureau. Retrieved from https://www.census.gov/content/ dam/Census/library/working-papers/2009/demo/bishaw-paa-col-3-4.pdf

Brady, D. (2003). Rethinking the sociological measurement of poverty. Social Forces, 81(3), 715-752. https://doi.org/10.1353/sof.2003.0025

Brooks, M. M. (2022). The changing landscape of affordable housing in the rural and urban United States, 1990-2016. Rural Sociology, Online First.

Bureau of Labor Statistics (BLS). (2010). Observations from the interagency technical working group developing a supplemental poverty measure. Retrieved from https://www.bls.gov/pir/spm/spm_twg_ observations.pdf

Bureau of Labor Statistics (BLS). (2021). Consumer Expenditures-2020. News Release. September 9, 2021. Retrieved from https://www.bls.gov/news.release/pdf/cesan.pdf 
Bureau of Economic Analysis. (2021). PARPP regional price parities by portion. BEA interactive data tables. Retrieved January 25, 2021 from https://apps.bea.gov/iTable/index_regional.cfm

Burns, K., Wilson, D., Fox, L. E. (2021). Two round of stimulus payments lifted 11.7 million people out of poverty during the pandemic in 2020. America counts: Stories behind the numbers. Retrieved January 26, 2021 from https:/www.census.gov/library/stories/2021/09/who-was-lifted-out-of-pover ty-by-stimulus-payments.html

Citro, C., \& Michael, R. T. (1995). Measuring poverty; a new approach. National Academies Press. https://doi.org/10.17226/4759

Duncan, G. J., Whitener, L. A., Duncan, G., Whitener, L. A., \& Weber, B. A. (2002). Lessons learned: Welfare reform and food assistance in rural America. Rural Dimensions of Welfare Reform, 16, 455-470. https://doi.org/10.17848/9781417508884.ch16

Energy Information Administration (EIA). (2021). Gasoline explained: Regional gasoline price differences. Retrieved from https://www.eia.gov/energyexplained/gasoline/regional-price-differences.php

Fan, J. X., Wen, M., \& Wan, N. (2017). Built environment and active commuting: Rural-urban differences in the U.S. SSM-Population. Health, 3, 435-441. https://doi.org/10.1016/j.ssmph.2017.05. 007

Farrigan, T. (2020). Rural poverty \& well-being. Economic research service. Retrieved from https:// www.ers.usda.gov/topics/rural-economy-population/rural-poverty-well-being/\#: :text=Accordingt othemostrecent, 12.6percentformetroareas

Fox, L. (2020). The supplemental poverty measure: 2019. The US Census Bureau, 8(September), 1-32. Retrieved from https://www.census.gov/library/publications/2020/demo/p60-272.html

Fox, L. E., \& Burns, K. (2021). The Supplemental Poverty Measure: 2020. Current Population Reports. US Census Bureau.

Ghelfi, L. M. (1988). About that lower cost of living in nonmetro areas. Rural Development Perspectives, $5,30-34$.

Glasgow, N., \& Brown, D. L. (2012). Rural ageing in the United States: Trends and contexts. Journal of Rural Studies, 28(4), 422-431. https://doi.org/10.1016/j.jrurstud.2012.01.002

Gyourko, J. (2009). Housing supply. Annual Review of Economics, 1(1), 295-318. https://doi.org/10. 1146/annurev.economics.050708.142907

Hall, C. M. (2010). Housing tourists: Accommodating short-term visitors. Rural housing, exurbanization, and amenity-driven development: Contrasting the "Haves" and the "Have Nots" (pp. 113-128). Taylor \& Francis.

Hamidi, S., Ewing, R., \& Renne, J. (2016). How affordable is HUD affordable housing? Housing Policy Debate, 26(3), 437-455. https://doi.org/10.1080/10511482.2015.1123753

Harvard JCHS. (2018). The State of the Nation's Housing, 2018. Retrieved from www.jchs.harvard.edu

Henning-Smith, C., Kozhimannil, K., \& Evenson, A. (2018). Addressing commuting as a public health issue: Strategies should differ by rurality. University of Minnesota Rural Health Research Center, (July), 1-5. Retrieved from http://rhrc.umn.edu/wp-content/files_mf/1532466620UMNpolicybriefC ommutingBehavior.pdf

Herbert, C., Hermann, A., \& Mccue, D. (2018). Measuring housing affordability: Assessing the 30-percent of income standard (pp. 1-25). The Joint Center for Housing Studies of Harvard University.

Holly, S., Hashem Pesaran, M., \& Yamagata, T. (2010). A spatio-temporal model of house prices in the USA. Journal of Econometrics, 158(1), 160-173. https://doi.org/10.1016/j.jeconom.2010.03.040

Hutto, N., Waldfogel, J., Kaushal, N., \& Garfinkel, I. (2011). Improving the measurement of poverty. Social Service Review, 85(1), 39-74. https://doi.org/10.1086/659129

Iceland, J. (2005). Measuring poverty: Theoretical and empirical considerations. Measurement Interdisciplinary Research \& Perspective, 3(4), 199-235. https://doi.org/10.1207/s15366359mea0304_1

Iceland, J. (2013). Methods of measuring poverty. Poverty in America: A handbook (3rd ed.). University of California Press. https://doi.org/10.1038/161624b0

Jensen, L., \& Ely, D. (2017). Measures of poverty and implications for portraits of rural hardship. In A. R. Tickamyer, J. Sherman, \& J. Warlick (Eds.), Rural poverty in the United States (pp. 67-83). Columbia University Press.

Johnson, K. M., \& Lichter, D. T. (2020). Metropolitan reclassification and the urbanization of rural America. Demography. https://doi.org/10.1007/s13524-020-00912-5

Kim, C., Sang, S., Chun, Y., \& Lee, W. (2012). Exploring urban commuting imbalance by jobs and gender. Applied Geography, 32(2), 532-545. 
Lipman, B. J. (2006). A heavy load: The combined housing and transportation burdens of working families. Retrieved from http://www.reconnectingamerica.org/assets/Uploads/pubheavylo ad1006.pdf

Loveridge, S., \& Paredes, D. (2018). Are rural costs of living lower? Evidence from a Big Mac Index Approach. International Regional Science Review, 41(3), 364-382. https://doi.org/10.1177/ 0160017616650488

Manson, S., Schroeder, J., Van Riper, D., \& Ruggles, S. (2021). 13.0, PUMS National Historical Geographic Information System: Version [Database]. University of Minnesota. https://doi.org/10. 18128/D050.V13.0

Marx, I. (2010). Exurbanization, homeownership, and the working poor. Rural housing, exurbanization, and amenity-driven development: Contrasting the "Haves" and the "Have Nots" (pp. 175-188). Routledge. https://doi.org/10.4324/9780429058103-19

Mazur, C. (2016). Homes on the range: Homeownership rates are higher in rural America. Retrieved from https://www.census.gov/newsroom/blogs/random-samplings/2016/12/homes_on_the_ range.html

McLafferty, S., \& Preston, V. (2019). Who has long commutes to low-wage jobs? Gender, race, and access to work in the New York region. Urban Geography, 40(9), 1270-1290.

Mueller, J. T. \& Santos-Lozada, A. R. (2022). The 2020 US Census differential privacy method introduces disproportionate discrepancies for rural and non-white populations. Population Research and Policy Review. Online First.

Needles Fletcher, C., Garasky, S. B., Jensen, H. H., \& Nielsen, R. B. (2010). Transportation access: A key employment barrier for rural low-income families. Journal of Poverty, 14(2), 123-144. https://doi.org/10.1080/10875541003711581

Nelson, P. B., \& Hines, J. D. (2018). Rural gentrification and networks of capital accumulation-A case study of Jackson, Wyoming. Environment and Planning A. https://doi.org/10.1177/03085 18X18778595

Nolan, L. B., Waldfogel, J., \& Wimer, C. (2017). Long-term trends in rural and urban poverty: New insights using a historical supplemental poverty measure. Annals of the American Academy of Political and Social Science, 672(1), 123-142. https://doi.org/10.1177/0002716217713174

Nord, M. (2000). Does it cost less to live in rural areas? Evidence from new data on food security and hunger*. Rural Sociology, 65(1), 104-125. https://doi.org/10.1111/j.1549-0831.2000.tb00345.x

Office of Management and Budget (2010). 2010 Standard for delineating metropolitan and micropolitan statistical areas; Notice. Technical Report Number123. Executive Office of the Vice President of the United States.

Pac, J., Nam, J., Waldfogel, J., \& Wimer, C. (2017). Young child poverty in the United States: Analyzing trends in poverty and the role of anti-poverty programs using the Supplemental Poverty Measure. Children and Youth Services Review, 74, 35-49. https://doi.org/10.1016/j.childyouth. 2017.01.022

Pacas, J. D., \& Davis, E. E. (2018). Moving into and out of rural poverty (Vol. 34). Institute for Research on Poverty.

Pacas, J. D., \& Rothwell, D. W. (2020). Why is poverty higher in rural america according to the supplemental poverty measure? An investigation of the geographic adjustment. Population Research and Policy Review. https://doi.org/10.1007/s11113-020-09612-9

Parolin, Z., Collyer, S., \& Curran, M. A. (2022). Sixth child tax credit payment kept 3.7 million children out of poverty in December. Poverty and social policy brief. Columbia University Center on Poverty and Social Policy.

Parolin, Z., \& Curran, M. A. (2021). Expanded child tax credit leads to further decline in child poverty in August 2021. In M. A. Curran (Ed.), Poverty and social policy fact sheet September 24, 2021. Columbia University Center on Poverty and Social Policy.

Pattillo, M. (2013). Housing: Commodity versus right. Annual Review of Sociology, 39(1), 509-531. https://doi.org/10.1146/annurev-soc-071312-145611

Renwick, T. (2011). Geographic adjustments of supplemental poverty measure thresholds: Using the American Community survey five-year data on housing costs. SEHSD Working Paper. Retrieved from http://www.census.gov/hhes/povmeas/methodology/supplemental/research/Renwick_SGE20 11.pdf

Renwick, T. (2020). Supplemental poverty measure. Brookings Institution. 
Ross, L., Drehobl, A., \& Stickles, B. (2018). The high cost of energy in rural America: Household energy burdens and opportunities for energy efficiency (pp. 1-60). American Council for an Energy-Efficient Economy.

Ruggles, S., Flood, S., Foster, S., Goeken, R., Pacas, J., Schouweiler, M., \& Sobek, M. (2021). IPUMS USA: Version 9.0. University of Minnesota. https://doi.org/10.18128/D010.V11.0

Scally, C., Gilbert, B., Hedman, C., Gold, A., \& Posey, L. (2018). Rental housing for a 21st century rural America: A platform for production. Retrieved from https://www.urban.org/sites/default/files/publi cation/99045/rental_housing_for_a_21st_century_rural_america.pdf

Semega, J., Kollar, M., Shrider, E. A., \& Creamer, J. F. (2020). Income and poverty in the United States: 2019 (pp. 60-270). U.S. Census Bureau Current Population Reports.

Short, K. (2011). The research supplemental poverty measure: 2010. Current Population Reports. P60241. United States Census Bureau. Retrieved January 25, from https://www2.census.gov/library/ publications/2011/demo/p60-241.pdf

Slack, T., Thiede, B. C., \& Jensen, L. (2019). Race, residence, and underemployment: Fifty years in comparative perspective, 1968-2017. Rural Sociology. https://doi.org/10.1111/ruso.12290

Smeeding, T. M. (2016). Poverty measurement. In D. Brady \& L. M. Burton (Eds.), The Oxford Handbook of the social science of povert (pp. 21-46). Oxford University Press. https://doi.org/10.1093/ oxfordhb/9780199914050.013.3

Thiede, B. C., \& Brooks, M. M. (2018). Child poverty across immigrant generations in the United States, 1993-2016: Evidence using the official and supplemental poverty measures. Demographic Research, 39, 1065-1080. https://doi.org/10.4054/DemRes.2018.39.40

Thiede, B., Kim, H., \& Valasik, M. (2018). The spatial concentration of America's rural poor population: A postrecession update. Rural Sociology, 83(1), 109-144.

Tickamyer, A. R., Sherman, J., \& Warlick, J. L. (Eds.). (2017). Rural poverty in the United States. Columbia University Press.

U.S. Census Bureau. (2017). Commuting times, median rents and language other than English use in the home on the rise. Retrieved from https://www.census.gov/newsroom/press-releases/2017/acs-5yr.html

U.S. Census Bureau. (2021). Public use microdata areas (PUMAs). Retrieved from https://www.census. gov/programs-surveys/geography/guidance/geo-areas/pumas.html

USDA Economic Research Service (USDA-ERS). (2013). County typology codes. Retrieved from https:// www.ers.usda.gov/data-products/county-typology-codes/.

Vega, W. A., \& Wallace, S. P. (2016). Affordable housing: A key lever to community health for older Americans. American Journal of Public Health, 106(4), 635-636. https://doi.org/10.2105/AJPH. 2015.303034

Ver Ploeg, M., \& Citro, C. F. (2008). Poverty measurement: Orshansky's original measures and the development of alternatives. Review of Agricultural Economics, 30(3), 581-590.

Warren, L., Fox, L., \& Ashley Edwards. (2020). The supplemental poverty measure in the survey of income and program participation. SEHSD Working Paper (Vol. 20). Retrieved from https://www. census.gov/content/dam/Census/library/working-papers/2020/demo/sehsd-wp2020-20.pdf

Weber, B., Jensen, L., Miller, K., Mosley, J., \& Fisher, M. (2005). A critical review of rural poverty literature: Is there truly a rural effect? International Regional Science Review, 28(4), 381-414.

Weber, B., \& Miller, K. (2017). Poverty in rural America then and now. In A. R. Tickamyer, J. Sherman, \& J. Warlick (Eds.), Rural poverty in the United States (pp. 28-64). Columbia University Press.

Wimer, C., Fox, L., Garfinkel, I., Kaushal, N., \& Waldfogel, J. (2016). Progress on poverty? New estimates of historical trends using an anchored supplemental poverty measure. Demography, 53(4), 1207-1218. https://doi.org/10.1007/s13524-016-0485-7

Winkler, R., Cheng, C., \& Golding, S. (2012). Boom or bust? Population dynamics in natural resourcedependent counties. In L. J. Kulcsár \& K. J. Curtis (Eds.), International handbook of rural demography (pp. 349-367). Dordrecht: Springer. https://doi.org/10.1007/978-94-007-1842-5_24

Wong, S., McLafferty, S. L., Planey, A. M., \& Preston, V. A. (2020). Disability, wages, and commuting in New York. Journal of Transport Geography, 87, 102818.

Ziliak, J. (2018). Are rural Americans still behind? (No. 34-2; Focus). Institute for Research on Poverty.

Zimmerman, J. N., Ham, S., \& Frank, S. M. (2008). Does it or doesn't it? Geographic differences and the costs of living. Rural Sociology, 73(3), 463-486. https://doi.org/10.1526/003601108785766561

Publisher's Note Springer Nature remains neutral with regard to jurisdictional claims in published maps and institutional affiliations. 